Journal of Thermal Engineering, Vol. 6, No. 2, Special Issue 11, pp. 99-113, March, 2020

Yildiz Technical University Press, Istanbul, Turkey

\title{
AN INVESTIGATIVE METHODOLOGY THROUGH SOLID MODELLING AND NUMERICAL ANALYSIS FOR DESIGNING A THERMO-ELECTRIC GENERATOR SYSTEM
}

\author{
Ekansh Chaturvedii, ${ }^{1,}$, Vijay Mamtani ${ }^{2}$
}

\begin{abstract}
This product development research project proposes a simplified novel methodology to design a thermoelectric generation (TEG) system. The iterative designs of complete assembly were prepared with the aid of Solidworks and the subsequent FEM analysis was aided by ANSYS fluent and transient thermal workbenches. The combustion chamber was subjected to a computational fluid dynamic study to generate flame profiles and to establish the temperature gradient distribution along the vertical length of inner surface of cylindrical chamber. The results of CFD analysis were then transported to the transient thermal workbench to calculate the charging time of whole system, which indeed founds the issues related to starting fuel efficiency of the system. A section model of the assembly was used to conduct the transient heat transfer analysis. The final results showed that after formation of a steady temperature gradient at the inner surface, the time required to completely charge up the system to achieve steady state came to be 30 minutes, which was found to be in good agreement with the operational constraints. Also, the temperature differences obtained between the hot and cold sides of TEG MARS modules were well within the safe limits. $\mathrm{NO}_{\mathrm{x}}$ emissions were also plotted and analysed.
\end{abstract}

Keywords: TEG, Seebeck Effect, FEM Analysis, Transient Heat Transfer, Charging Time

\section{INTRODUCTION}

Patented by Wallace Shakun et. al. in 1988, a thermoelectric generator module which is formed with a hot side heat exchanger having extruded fins on one surface and in contact with a series of individual thermoelectric semiconductor modules on the opposite side of the exchanger. A cold side heat exchanger attached to the opposite side of the semiconductor modules from the hot side heat exchanger, producing a thermal gradient across the semiconductor modules. The semiconductor modules are placed in an arranged pattern so that a maximum of heat flow through the modules is produced. Each semiconductor module is connected electrically to each other so that their output may be combined to produce a large quantity of electric power. A series of generator modules may be interconnected in a series or parallel combination to form a thermoelectric generator of varying power output [1, 2]. Operation of Thermoelectric Power Generating products is based on a phenomenon of direct conversion of heat flow into electromotive force. It was discovered in 1821 by Thomas Seebeck. The basic element of thermoelectric devices is thermocouple (fig.1) [3]. If temperature gradient arises across the junctions of dissimilar conductors (or semiconductors) electromotive force would be generated. If thermocouple would be connected to external electrical load electric current will flows through the circuit.

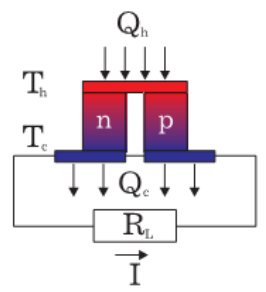

Figure 1. Schematic representation of TEG system

This paper was recommended for publication in revised form by Regional Editor Tolga Taner

${ }^{1}$ Department of Mechanical Engineering, Maulana Azad National Institute of Technology, India

${ }^{2}$ Department of Electrical Engineering, Maulana Azad National Institute of Technology, India

*E-mail address: ekanshchat96@gmail.com

Orcid id: ${ }^{1}$ 0000-0002-8090-8953, ${ }^{2}$ 0000-0001-6420-9637

Manuscript Received 22 June 2018, Accepted 21 September 2018 
where, $Q_{h}$ and $Q_{c}$ denote heat entering at hot side and heat emanating from cold side respectively; $T_{h}$ and $T_{c}$ represent temperatures at the corresponding sides and I is the current flowing in the electric circuit across the load resistance $\mathrm{R}_{\mathrm{L}}$.

Another important point is effective heat removal from cooling side of module with a goal to provide lowest temperature on it. In the real life the engineer commonly is dealing with existing thermal power sources which have definite output parameters (sizes, surface material or it's thermal resistance, thermal flow density, temperature and it possible changes in time). Also engineer could be limited by the space in his construction of the cooling heat sink, its weight, the type of heat removal in to ambient (by air with natural or forced convection, by liquid, etc.). Another important point is the way of module mounting (the glue, thermal grease paste with tie bolts or soldering). On the way of heat flow from the source to environment there are several separate thermal resistances of the parts of construction. Fig. 2 shows a block diagram of the participating resistances in the path of heat dissipation from heat source to environment [3].

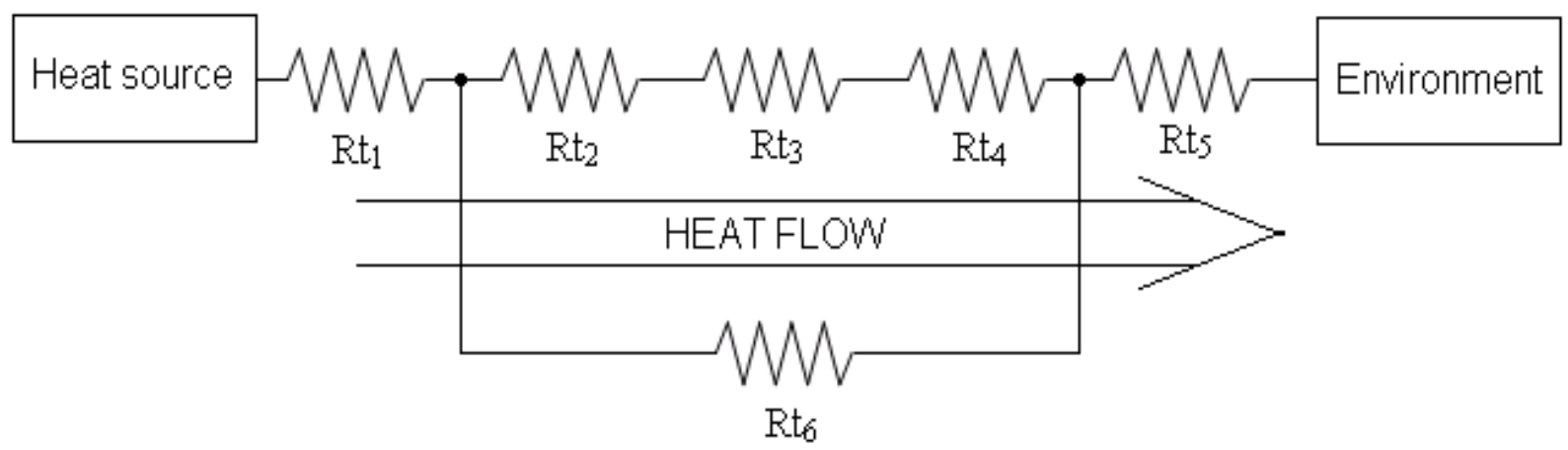

Figure 2. Block-scheme of thermal resistances

where, $\mathrm{Rt}_{1}$ is thermal resistance of heat source; $\mathrm{Rt}_{2}$ and $\mathrm{Rt}_{4}$ are thermal resistances of thermo-conductive paste, glue or mounting solder; $\mathrm{Rt}_{3}$ is thermal resistance of module construction (ceramics, thermo electric elements, assembly solder etc); $\mathrm{Rt}_{5}$ is thermal resistance of cooling heat sink and $\mathrm{Rt}_{6}$ is parasitic thermal resistance of construction.

This research work proposes a novel simplified methodology to design and simulate the results pertaining to deciding parameters before attempting to build a prototype. The importance of the research been done in this domain can be understood by the fact that this system, if realized for commercial purpose, would not only utilize waste heat sources to produce electricity but also because of having no moving components, would engender no mechanical losses as in case of conventional turbine based plants.

Yet other facts that highlight the urgent necessity to make this system commercially possible are the previous researches done over it. Changwei Liu et. al. [4] attempted an experimental study over the prototype of a $500 \mathrm{~W}$ unit, the same this research work deals with but on a numerical analysis stage. The study including the multiphysical aspects such as flow simulations, combustion simulations and transient analysis haven't been conducted earlier using softwares but have been experimented directly on the prototypes, which indeed is a costly method of testing as far as commercial implementations are concerned with respect to the producing company. This research, as it reveals ahead, has succeeded to achieve a temperature difference of $296^{\circ} \mathrm{C}$ while the involved authors of reference [4] achieved about $200^{\circ} \mathrm{C}$ to achieve the same output. O.M. Al-Habahbeh et. al. [5] conducted a simulation study to solve the mathematical formulations with source being a concentrated solar receiver. Their concluding points emphasized the economical and commercial aspects of a TEG compared with Photo-voltaic cell, a much renowned alternative, which concluded the limitations as well as assets associated with TEG. TEG produced power per dollar is 73\% of that produced by PVC. However, TEG is better than PVC in terms of weight and size. It 
requires only $0.7 \%$ of the space required by PVC. In addition, the TEG weight is only $0.8 \%$ of the corresponding PVC weight.

Ngendahayo Aimable also designed a TEG system targeting the industrial waste heat energy sources to implement the use of TEG modules. A very noticeable point that appeared in the thesis stated the very conspicuous but often ignored heat loss in case of automobiles which is about $66 \%$ of the input energy [6]. Hence, another case study conducted by Z.B. Tang et. al. pertained to the use of TEG modules in automotive systems to recover electrical energy from the wasted heat through exhausts as well as combustion chambers of the engines [7]. This although is a very costly way to support the electrical systems of a vehicle, with currently available technology, but indeed efficient in long term usage as it eliminates use of batteries.

Hence, to some extent the work presented in this paper is not only a novel, simplified and cost effective method to solve the problem but has also succeeded to produce an improved design.

\section{METHODOLOGY AND ANALYSIS Design Assembly Constituent Components}

The assembly build shown in Fig. 3, encaged in an AISI 1080 steel cage, constitutes of a grey cast iron combustion chamber whose lateral hexagonal surface is enveloped within an aluminum AL-6016-H casting. Over the 6 surfaces of the aluminum cover are mounted MARS TEG modules with the help of ceramic paste; the module surface in contact with aluminum hence forms the hot side surface. The other surface, cold side surface is kept in contact with aluminum AL-6016-H fin panels. Fig. 4 shows a cut section of the same assembly showing internal components like burner and ceramic refractory lid between exhaust pipe and combustion chamber, to avoid loss of heat flux. The areas of aluminum envelope not in contact with fin panels or module and the surfaced of exhaust pipe in air contact are supposed to be kept insulated (insulation not shown).

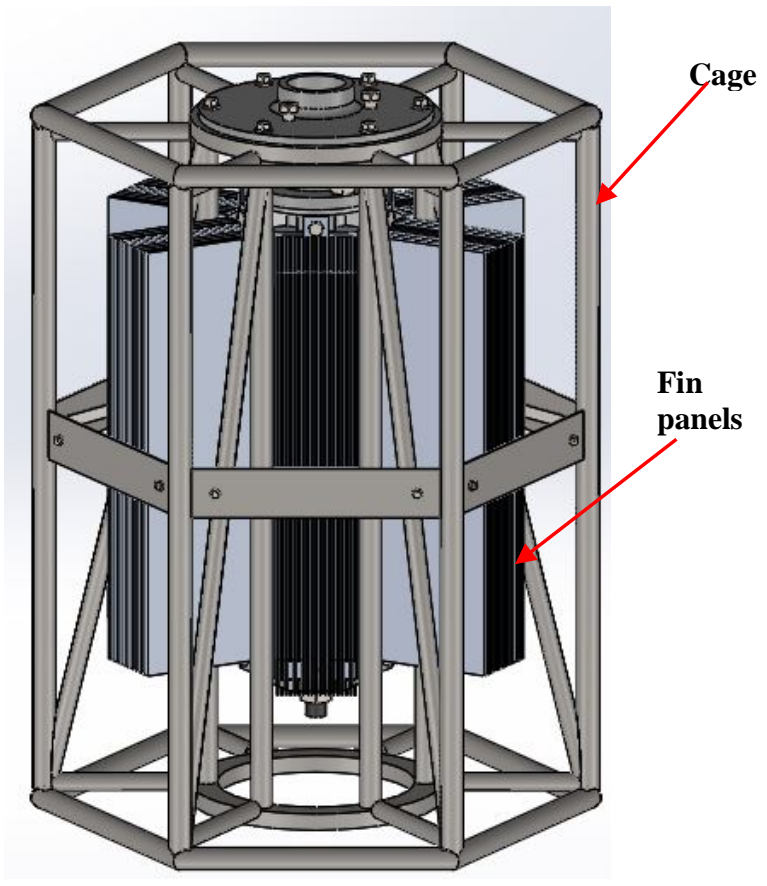

Figure 3. Assembled unit of a TEG system

It is to be clearly mentioned before proceeding to the following rubrics, that this particular assembly size was built to accommodate enough volumetric gas combustion so as to generate $500 \mathrm{~W}$ of electrical power [8,9]. 


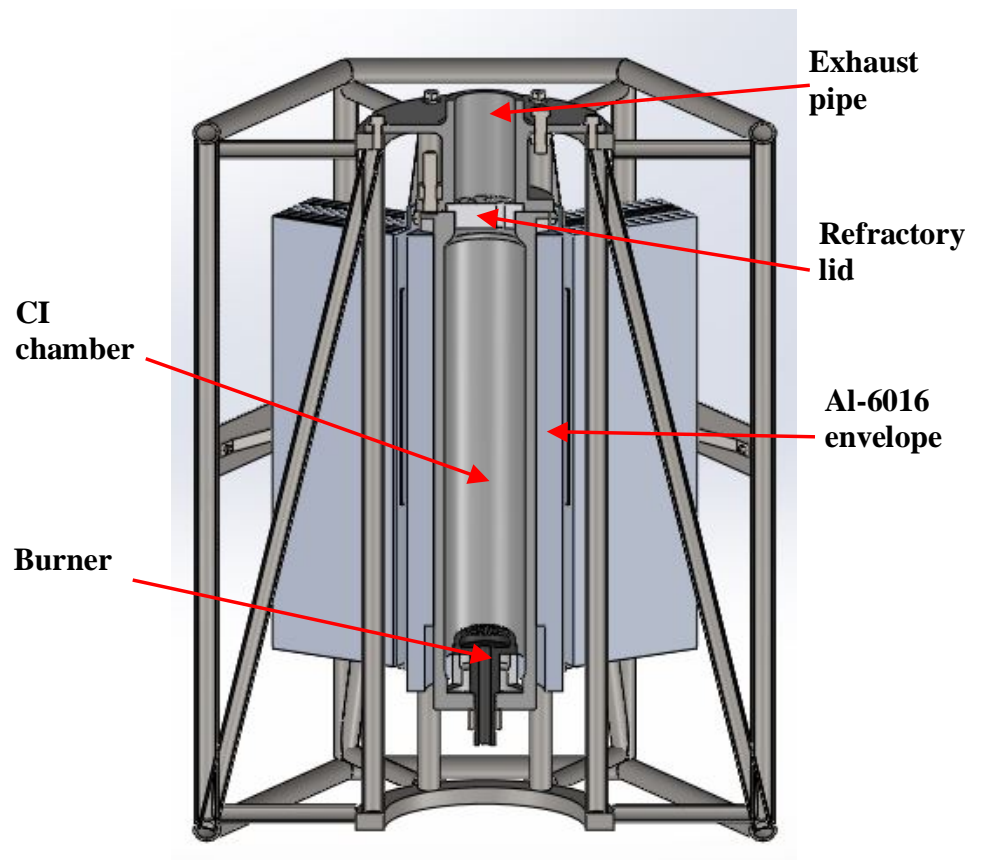

Figure 4. Cut-section of assembly showing components

\section{Heat Transfer Mechanism Through Chamber}

As described by Fig. 2 the heat would flow across solid bodies impeded by their individual thermal resistances in sequential orientation with respect to each other. The mechanism of single dimensional steady state heat transfer in case of cylinder having radius $r$ (combustion chamber and envelope) is governed by Fourier's law of heat conduction with heat generation $g$ for variable conductivity of material [10] given as:

$$
\frac{1}{r} \frac{\partial}{\partial t}\left\{r k \frac{\partial T}{\partial r}\right\}+g=\rho C \frac{\partial T}{\partial t}
$$

where $\rho$ represents the density and $C$ represents the specific heat capacity of the material. The equation (1) further reduces to a simpler form depicting transient heat flow mechanism; if conductivity $k$ of material is considered constant; that is independent of the temperature $T$; and is given as:

$$
\frac{1}{r} \frac{\partial}{\partial t}\left\{r \frac{\partial T}{\partial r}\right\}+\frac{g}{k}=\frac{1}{\alpha} \frac{\partial T}{\partial t}
$$

where, $\alpha$ is the thermal diffusivity of the material.

As further explained in the reference [10], the aforementioned equations converge to a much transformed equation specific to heat transfer in cylinders, which includes radiation and convective dissipations as well. The equation is given as:

$$
\dot{Q}=\frac{T_{\infty 1}-T_{2}}{R_{c o n v .1}+R_{c y l .1}}=\frac{T_{\infty 1}-T_{2}}{\frac{1}{h_{1}\left(2 \pi r_{1} L\right)}+\frac{\ln \left(r_{2} / r_{1}\right)}{2 \pi L k_{1}}}
$$


where $T_{\infty 1}$ represents ambient temperature, $T_{2}$ represents inner surface temperature, $R_{\text {conv. } 1}$ is the convective thermal resistance and $R_{c y l .1}$ is the thermal resistance of cylinder material.

L Chen et. al. stated the conditions conducive to maximum power and efficiency of a TEG system by conducting a mathematical study and establishing a generalized heat transfer law [11]. It was found that the external heat transfer law does affect the characteristics and optimal performance of the thermoelectric device. The generalized heat transfer law included Seebeck effect; Fourier effect, Joule effect and Thomson effect, and external heat transfer were taken into account in the model. Since this study strictly concerns with thermal performance parameters, therefore, Fourier's equation and its relevant derivatives were considered best for the case.

\section{Heat Transfer Mechanism Through Fins}

The purpose of fins is to enhance convective heat transfer from surfaces. The primary mechanism behind the operation of fins is to increase the effective heat transfer area of a surface. They are commonly used in situations in which cooling is attained via free (or natural) convection - for which the heat transfer coefficients $h$ are relatively small, as in this case where the fin panels are solely being used to maintain cold side temperature of TEG module to a least possible value. The mechanism is governed by the following equation, derived by substitution of laws of conduction and convection, taken from reference [12]:

$$
\left.\left.-k A_{c}(x) \frac{d T}{d x}\right]_{x}+k A_{c}(x+\Delta x) \frac{d T}{d x}\right]_{x+\Delta x}-h d A_{s}(x)\left(T-T_{\infty}\right)=0
$$

To further simplify the problem the fin assumed to have an adiabatic tip. The heat transfer is:

$$
Q=\sqrt{h P k A c}\left(T_{b}-T_{\infty}\right) \tanh m L
$$

where, $x$ is the distance of element from root of fin, $A_{c}$ is the area of cross section, $A_{s}$ is the surface area exposed to ambience and $\mathrm{P}$ is the perimeter. Here, $m$ is defined as $\sqrt{h P / k A c}$ [12].

The transient state thermal workbench solver utilizes all the aforementioned equations as a basic algorithm to solve the problem concerned with heat transfer.

\section{Boundary Condition Data for CFD Simulation}

W. Li et. al. adopted a similar methodology to simulate thermal as well as electrical performances over a design [13] which was although not meant to be used for commercial purpose but indeed founded this study. This study includes the need of studying the combustion mechanism for constraining parameters pertaining to fuel characteristics and consumption limits, which directly control the thermal as well as electrical performance of complete system. Hence, for a commercial implementation, the design has undergone a complete change and hence the associated parameters require a CFD study.

The Fig. 5 shows the planar section geometry of the combustion chamber along with respectively named boundary edges subjected to various behavioral conditions [14]. This geometry was used to generate flame profile of burning natural gas in presence of atmospheric air. The fuel, as briefed earlier, was chosen as natural gas which comprises nearly $90 \%$ methane. A close approximation of the reacting components of fuel taken for simulation comprised $90 \%$ methane, $5 \%$ propane and $5 \%$ butane by volume. This is indeed a close emulation of natural gas properties as far as combustion characteristics are concerned. The volume flow rate of inlet gas supply was taken from the Ecogen technology catalogue report [8] as $48 \mathrm{~m}^{3}$ per day; which is equivalent to $0.000367 \mathrm{~kg} / \mathrm{s}$ when converted. The above shown named selected boundaries were subjected to following boundary conditions [15, 16]:

\section{Air Inlet}

i. Type: Pressure inlet vent

ii. Initial gauge pressure: $1 \mathrm{~atm}$ 
iii. Turbulence specification: Intensity $=5 \%$; Hydraulic diameter $=42 \mathrm{~mm}$

iv. Temperature: $35^{\circ} \mathrm{C}$

v. Species mass fractions: $\mathrm{O}_{2}: 23 \%$

Intensity is kept $5 \%$ because the flow is from a vent, which can be considered as a medium turbulence flow system having limits between $1 \%$ to $5 \%$ intensity; and evidently the maximum possible limit was selected [17].

\section{Gas inlet}

i. Type: mass flow inlet

ii. Mass flow rate: $0.000367 \mathrm{Kg} / \mathrm{s}$ [4]

iii. Gauge pressure: $1 \mathrm{~atm}$

iv. Turbulence specifications: Intensity: 20\%; Hyd. Diameter: 70mm

v. Temperature: 30 deg C

vi. Species Mass fraction: $\mathrm{CH}_{4}=0.9 ; \mathrm{C}_{3} \mathrm{H}_{8}=0.05 ; \mathrm{C}_{4} \mathrm{H}_{10}=0.05$.

Gas inlet was considered as a high turbulence flow system and thus the intensity value was chosen to be $20 \%$ [17].

\section{Outlet/exhaust}

i. Type: pressure outlet

ii. Gauge pressure: $1 \mathrm{~atm}$

iii. Specifications for turbulence: Intensity: 10\%; Hyd. Dia: 80mm (Fig. 5)

iv. Species mass fractions: $\mathrm{CO}_{2}=0.424 ; \mathrm{O}_{2}=0.2 ; \mathrm{H}_{2} \mathrm{O}=0.556$

\section{Wall}

i. Stationary smooth wall with no slip condition

ii.Equivalent wall thickness 90mm; Material: Aluminium

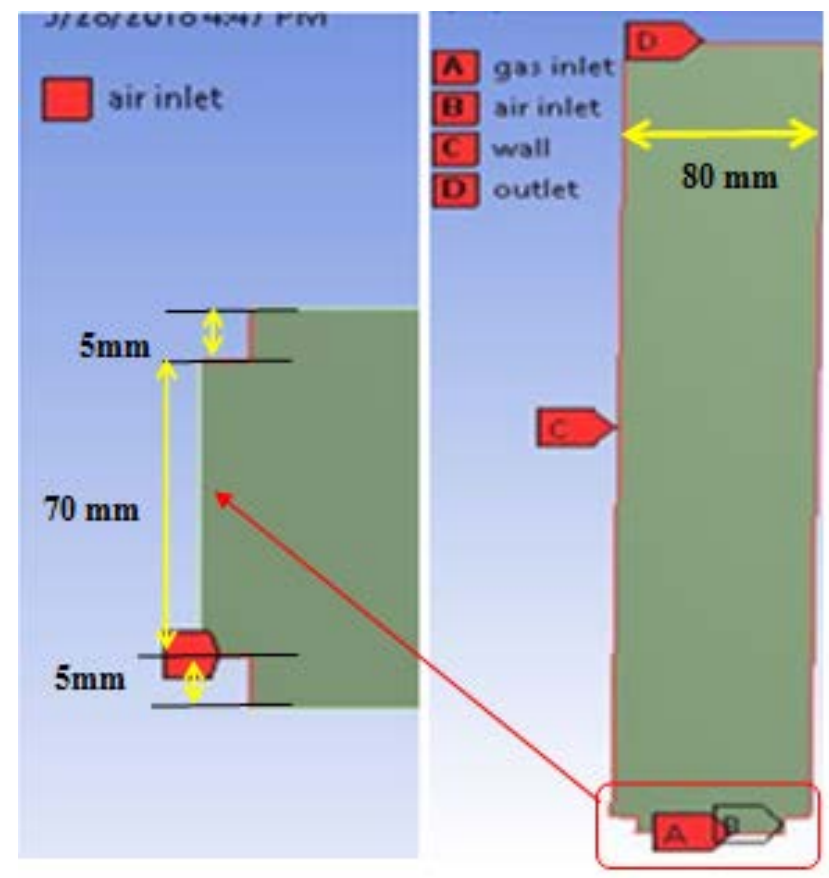

Figure 5. Planar geometry of combustion chamber with named selections

The aforementioned concentrations of various species were taken as approximate outcomes after solving stoichiometric calculations of chemical reaction equations of methane, propane and butane. The solver settings chosen for conducting the simulation included following major specifications [18]: 


\section{Solver}
a. Type: Pressure based study
b. Absolute velocity formulation
c. Steady state
d. Planar section of the chamber under study
e. Gravitational influence applied

\section{Model}

a. Standard K-epsilon, energy equation: ON, standard wall function.

b. Reactions: Species transport, volumetric reaction employing inlet diffusion; Reactants: methane air mixture, turbulence: eddy dissipation

c. NOx calculator: ON

d. Specific heat Cp governed by mixing laws, thermal conductivity kept constant as $0.0454 \mathrm{w} / \mathrm{m}-\mathrm{k}$, viscosity kept constant.

\section{Analysis Settings For Transient Thermal Simulation}

For transient thermal analysis, an axially symmetric section of the assembly was taken as the subject geometry (shown in Fig. 6) in order to save time while meshing and solver processing. A reference may be taken from Fig. 4 for better visualisation. The heat generated by combustion of fuels gases passes through walls of cast iron and aluminium envelope upon which hot side of module rests. The module's cold side is attached to the fin panel which dissipates heat and maintains a cooler temperature at the cold side of module. The temperature difference thus generated is used by module to produce electric energy. Bekir Sami Yilbas et. al. [19] found the necessity to minimise the cold side temperature and increase the difference for maximising the working efficiency of TEG module. All the 6 modules are connected with each other in series to produce power. Fig 7 shows a schematic representation of heat transfer through the system.

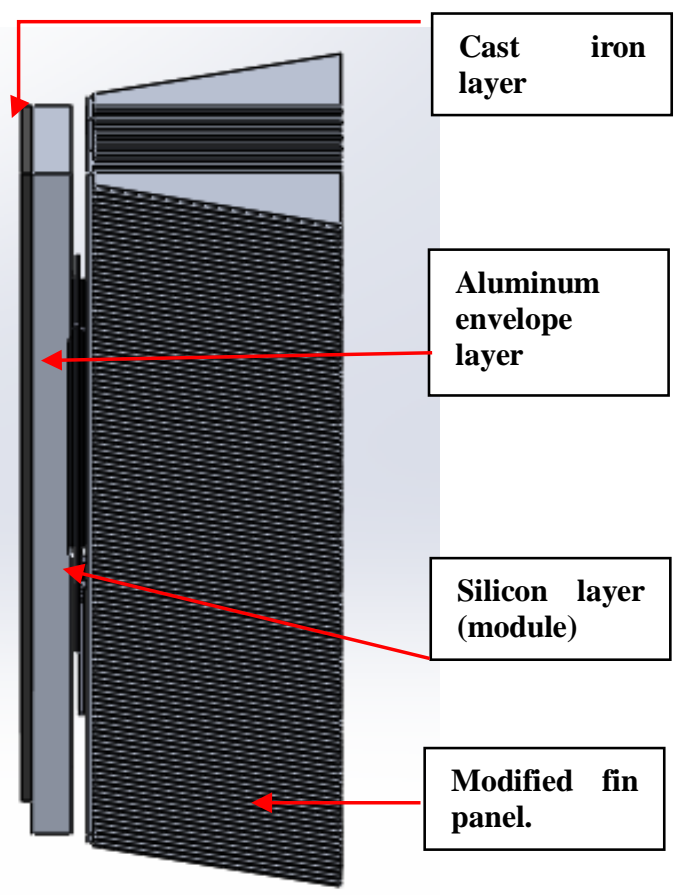

Figure 6. Section model of assembly for transient analysis 


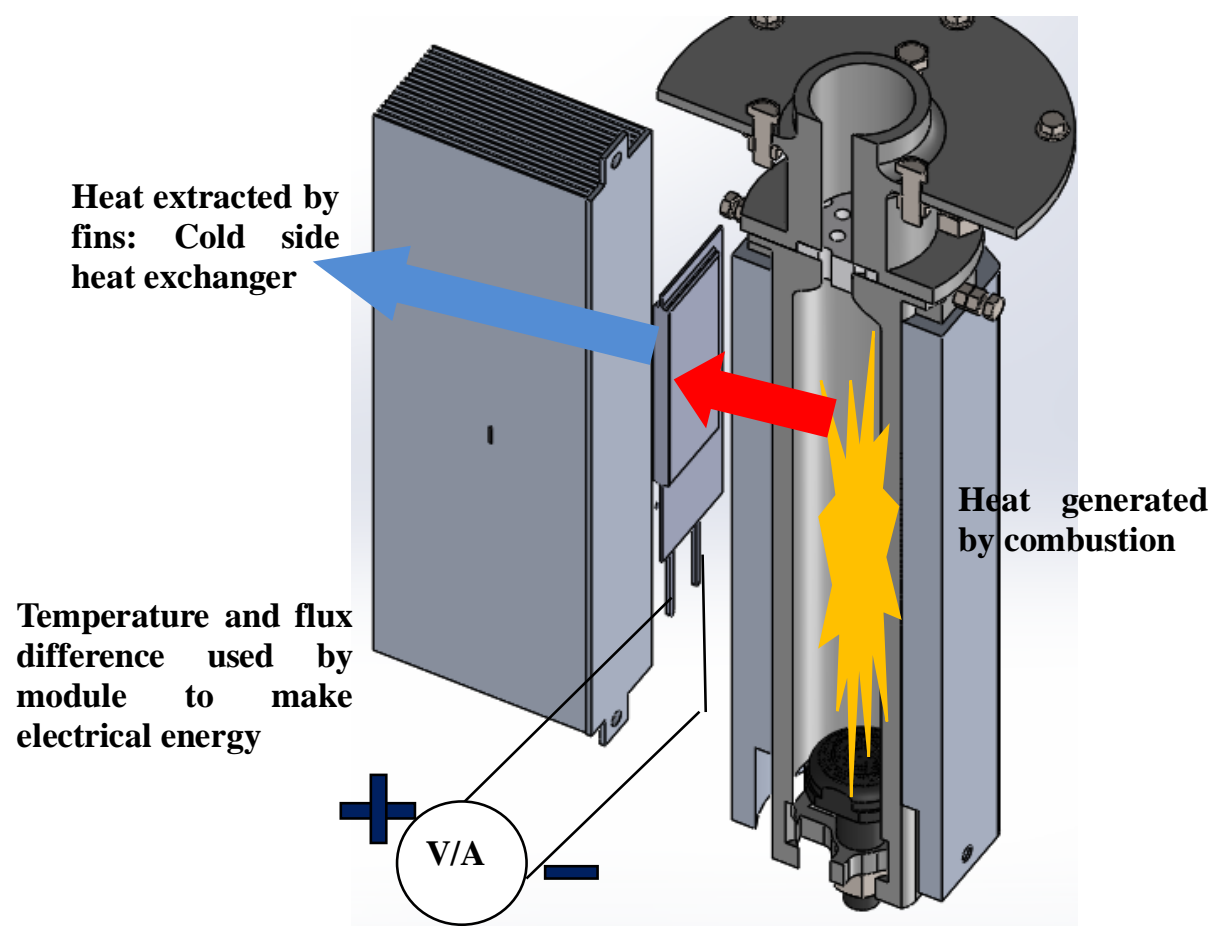

Figure 7. Operation of the designed TEG system: Section view

It is conspicuous that a modified fin panel (Fig. 6) was incorporated here, having horizontally protruding fins from flat surfaces of the vertical fins at extreme ends. This modification, though not shown in fig 3, 4 and 7, has been done later to increase the heat dissipation capacity of fins. Yet another important fact can be noticed that material assigned for the module body was silicon, though usually they are made of silicon-germanium alloy [20] or Bismuth-Telluride [21] and the ceramic paste layers were ignored. Further, the position of placement of the TEG module was chosen so that the hot side of it lies at the safe zone of the temperature band formed on Aluminum envelope wall, while simultaneously covering maximum surface area to maximize the efficiency [21]. The properties of silicon relevant to the study are shown in Table 1 and Table 2.

Table 1. Mechanical properties of silicon (anisotropic)

\begin{tabular}{|c|c|}
\hline Density & $2330 \mathrm{Kg} / \mathrm{m}^{3}$ \\
\hline Specific heat & $702 \mathrm{~J} / \mathrm{Kg}{ }^{0} \mathrm{C}$ \\
\hline Thermal conductivity & $124 \mathrm{~W} / \mathrm{m}^{0} \mathrm{C}$ \\
\hline Resistivity & $1 \times 10^{-4} \mathrm{ohm} \mathrm{m}$ \\
\hline
\end{tabular}

Table 2. Variation of silicon's coefficient of thermal expansion with temperature

\begin{tabular}{|c|c|}
\hline $\begin{array}{c}\text { Coefficient of thermal } \\
\text { expansion }\left(/{ }^{\circ} \mathrm{C}\right)\end{array}$ & $\begin{array}{c}\text { Temperature }\left({ }^{\circ} \mathrm{C}\right) \text { \{reference } \\
\text { temperature being } 22^{\circ} \mathrm{C} \text { \} }\end{array}$ \\
\hline $2.46 \times 10^{-6}$ & 20 \\
\hline $3.61 \times 10^{-6}$ & 250 \\
\hline $4.15 \times 10^{-6}$ & 500 \\
\hline $4.44 \times 10^{-6}$ & 1000 \\
\hline $4.44 \times 10^{-6}$ & 1500 \\
\hline
\end{tabular}


Material assignment is followed by the application of boundary conditions. The results of the prior conducted CFD simulation are transferred to the transient thermal workbench [22]. These parameters, which include developed temperature gradient and heat flux band, were applied over the inner side of CI layer (left most face in Fig. 6). The free surfaces of aluminum layer which were neither in contact with module nor with the fin panel were set as perfectly insulated ones; whereas all the surfaces of fin panel, except the one in contact with module were subjected to stagnant air free convection having ambience temperature as $35{ }^{0} \mathrm{C}$, which is usually the average temperature in Indian sub-tropical region, with a constant $h$ value being $10 \mathrm{~W} / \mathrm{m}^{2} \mathrm{~K}$ [23, 24].

\section{RESULTS AND DISCUSSION}

Fig. 8 shows contours representing static temperature distribution over the face of the geometry plane. It represents the temperatures at different portions of a steady state propagating flame. Fig. 9 shows the temperature gradient at the inner wall of the combustion chamber. The parameter on $\mathrm{X}$ - axis is the length from the burner end to the lid end.

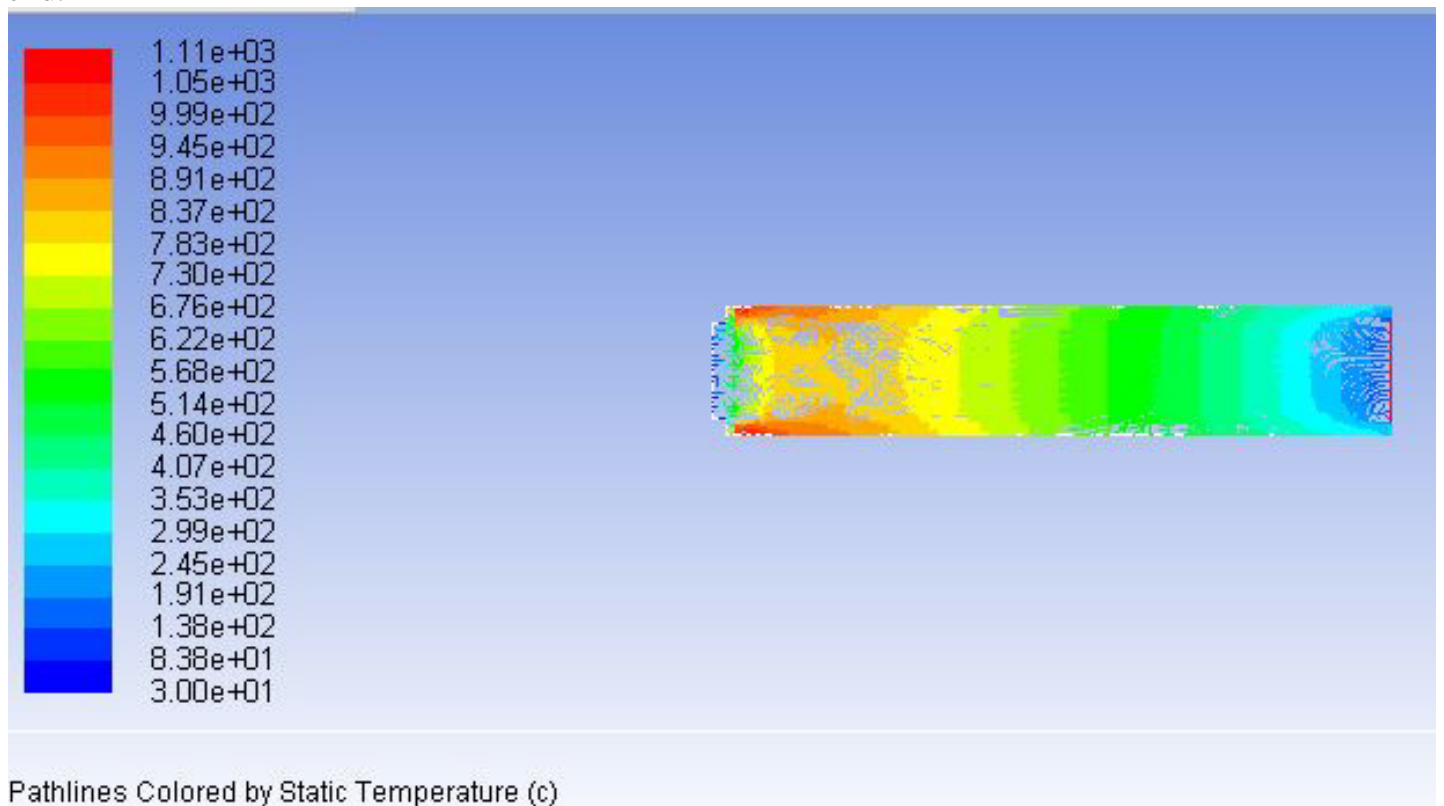

Pathlines Colored by Static Temperature (c)

Figure 8. Temperature contours of flame propagation

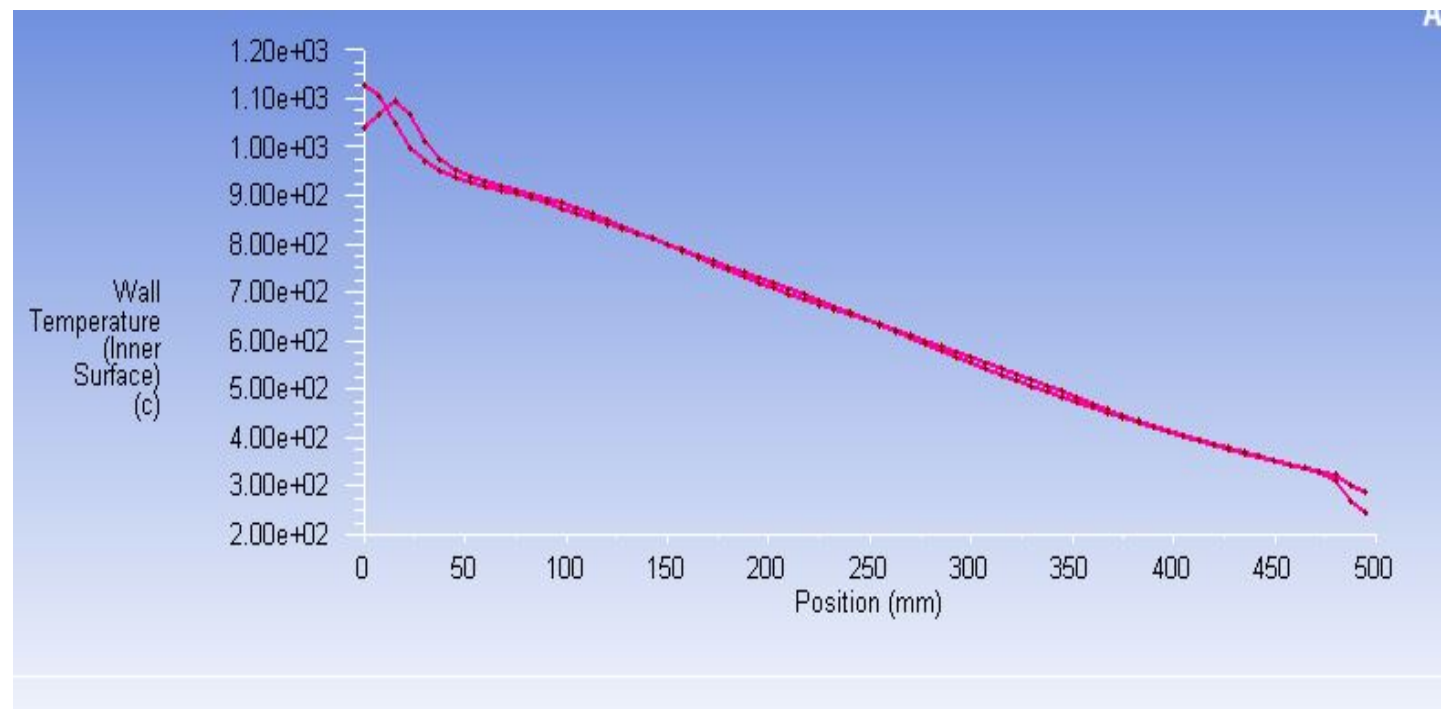

Figure 9. Temperature gradient along the length of the wall 
Fig, 10 shows the contours representing total surface heat flux. It was observed that the heat flux across the wall surface increased along the length of combustion chamber and was maximum at the lid end. Fig. 11 shows the corresponding distribution of wall function heat transfer coefficient.

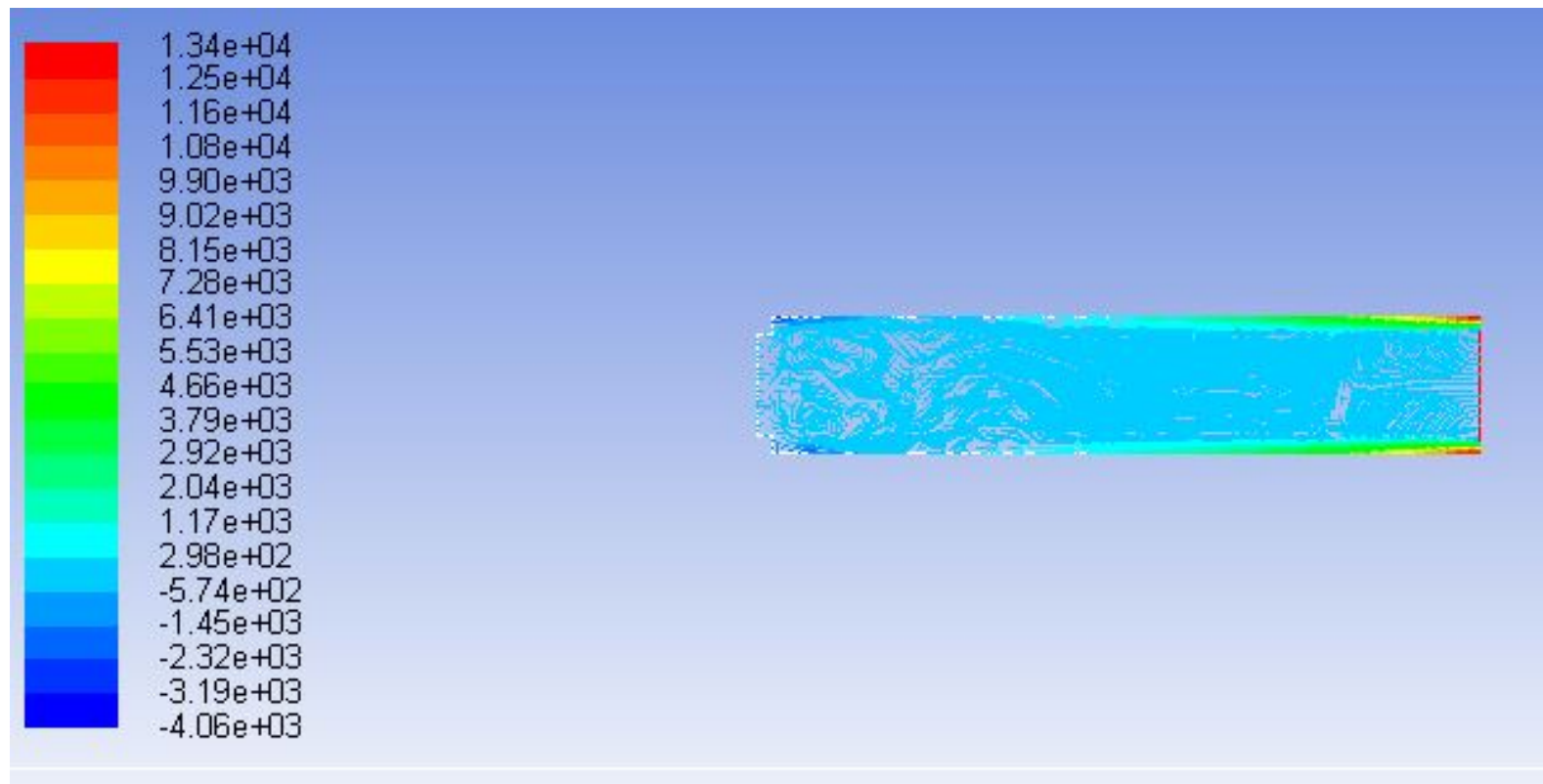

Pathlines Colored by Total Surface Heat Flux (w/m2)

Figure 10. Total surface heat flux contour spread over the planar geometry

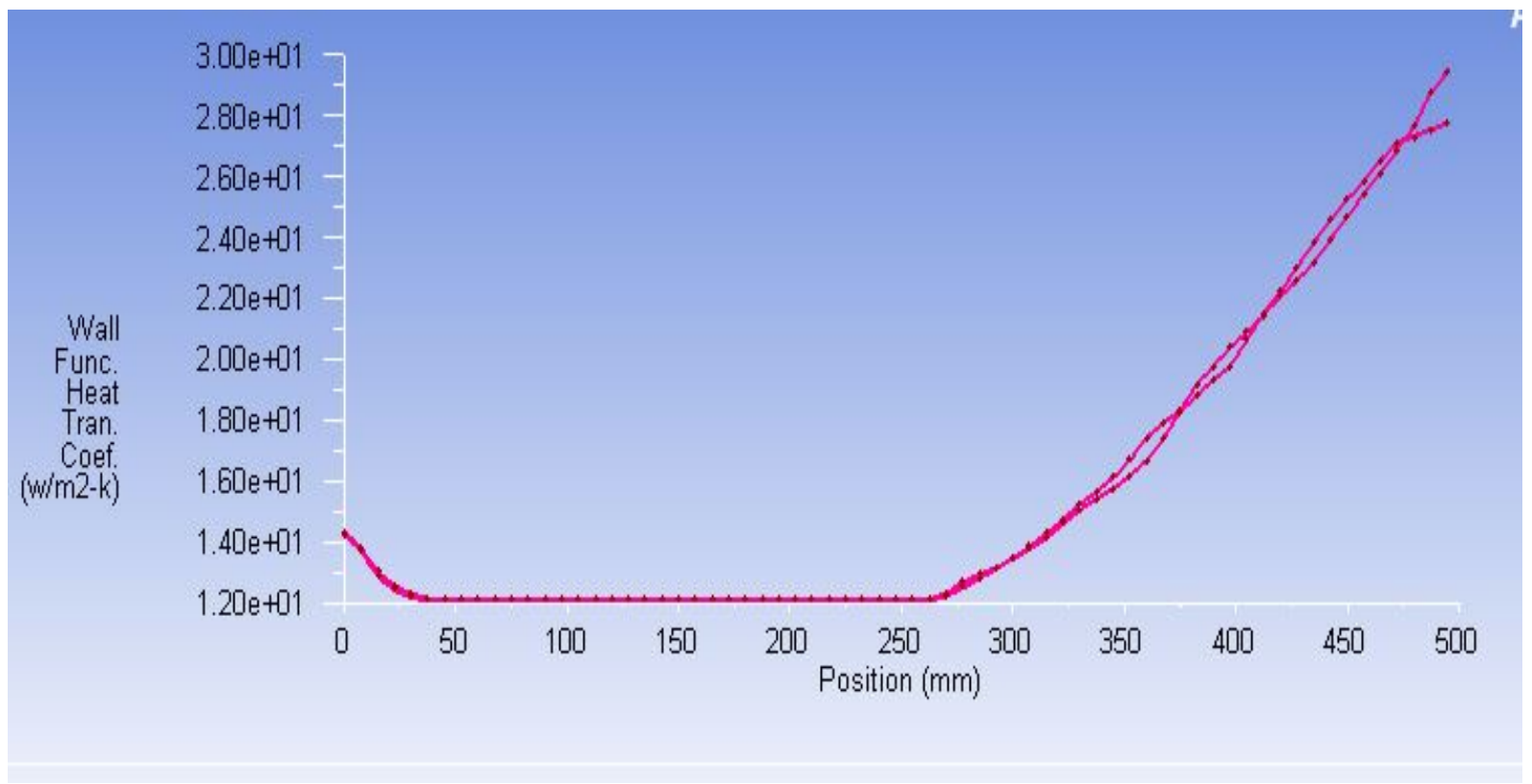

Figure 11. Wall surface heat transfer coefficient variation along the length of combustion chamber

Fig. 12 and Fig. 13 represent the mass fraction distribution contours of pollutants $\mathrm{CO}_{2}$ and $\mathrm{NO}_{\mathrm{x}}$ respectively. As observed, the presence of significant nitrogen content in presence of excess $\mathrm{O}_{2}$ generated moderate $\mathrm{NO}_{\mathrm{x}}$ amounts. Fig. 14 shows the mass fraction distribution of fuel gases. A complete combustion was observed. 
Journal of Thermal Engineering, Technical Note, Vol. 6, No. 2, Special Issue 11, pp. 99-113, March, 2020

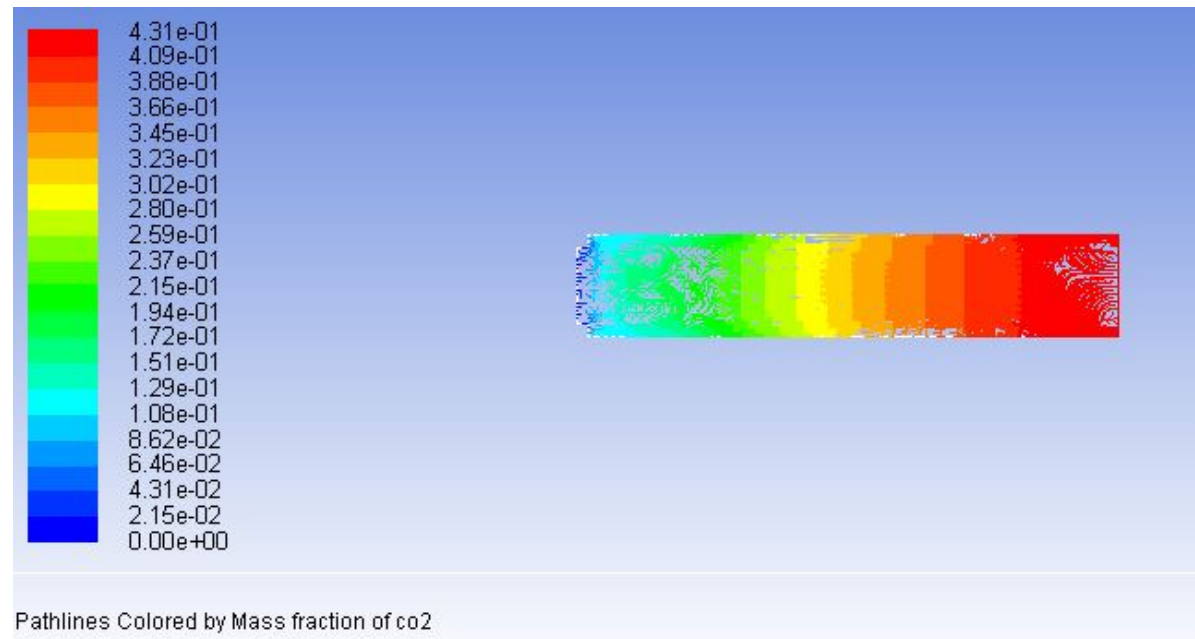

Figure 12. $\mathrm{CO}_{2}$ mass fraction distribution

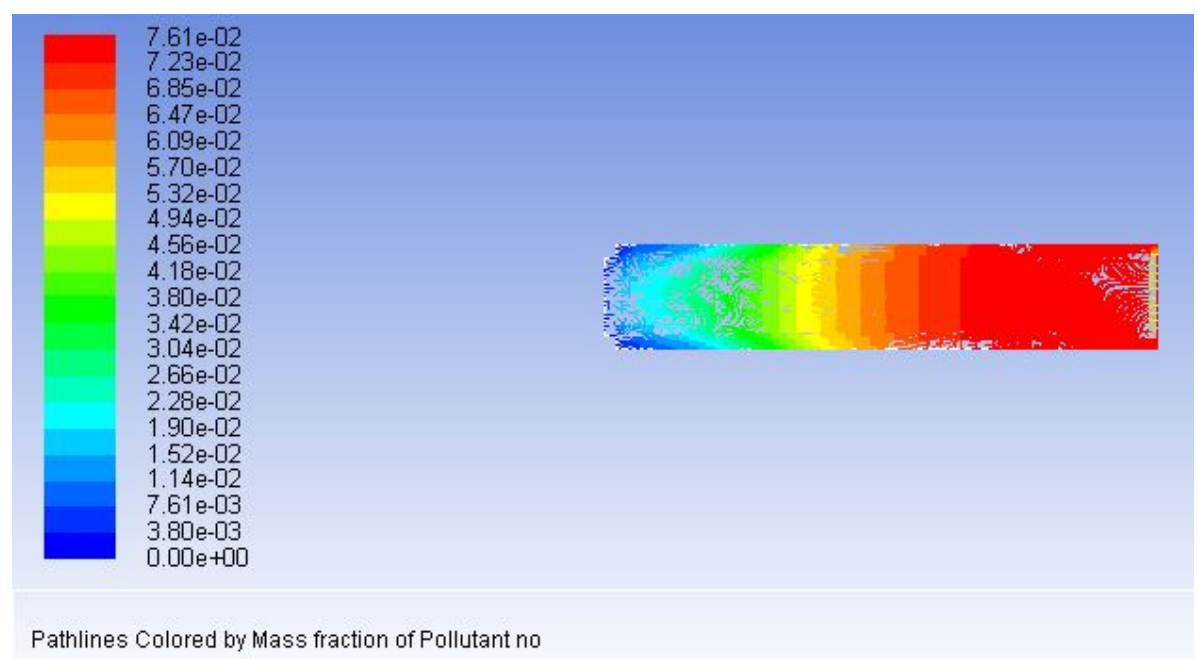

Figure 13. $\mathrm{NO}_{\mathrm{x}}$ mass fraction distribution

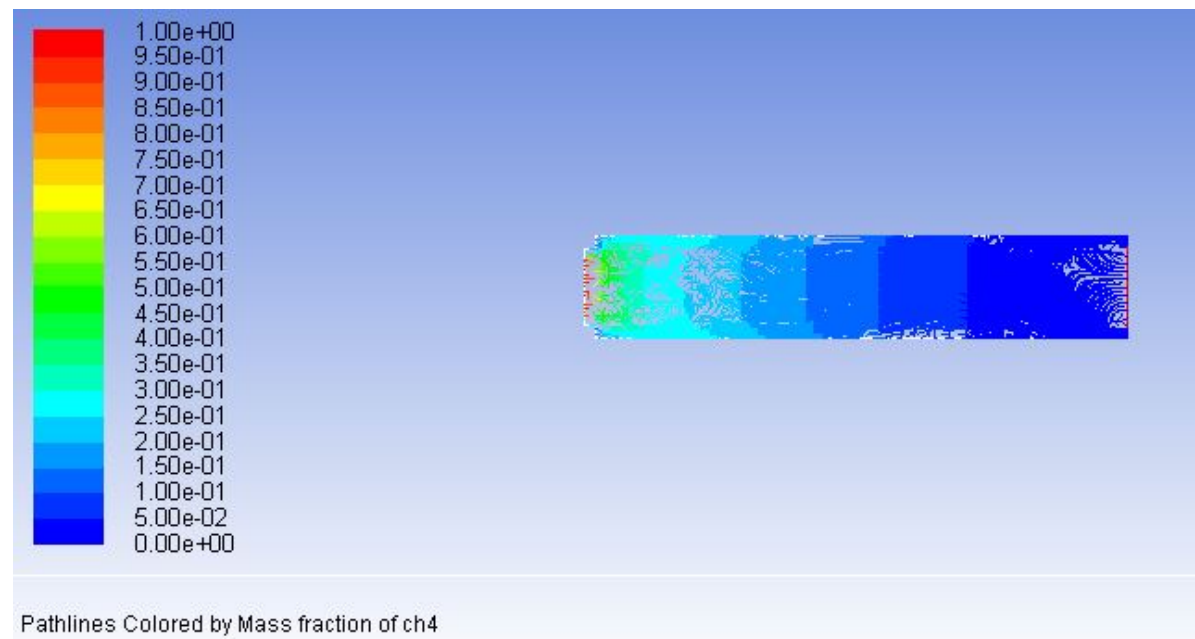

Figure 14. Fuel gases mass fraction distribution 
The Fig 15 shows the transient period of the heat transfer process that was taken by system to achieve a steady state. It was found to be 1777 seconds $(29.61 \mathrm{~min})$. Fig. 16 shows the probed maximum and minimum temperatures at the hot side and cold side of module respectively. Maximum temperature difference came out to be $296^{0} \mathrm{C}$.

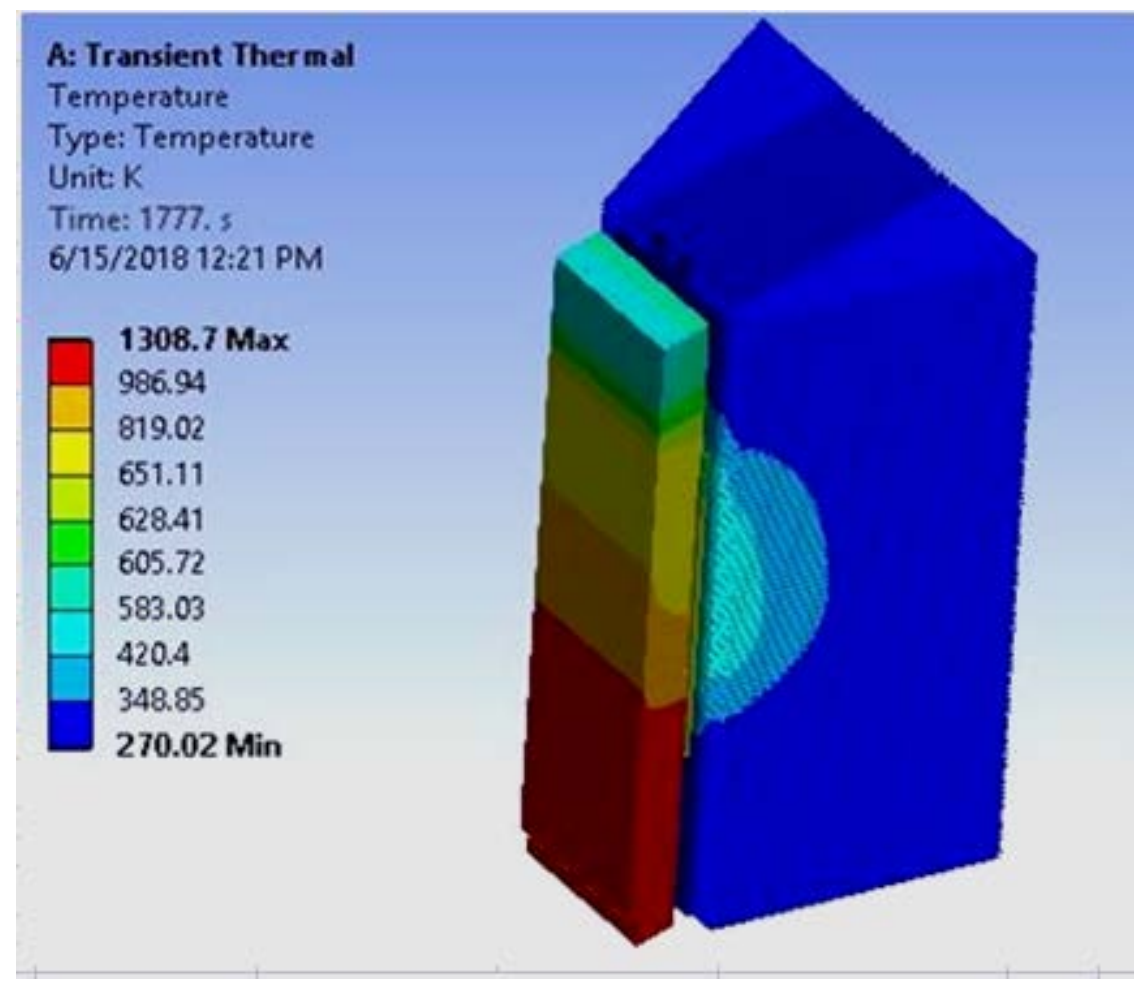

Figure 15. Transient period (Charging time) for TEG system (from hot end to cold end)

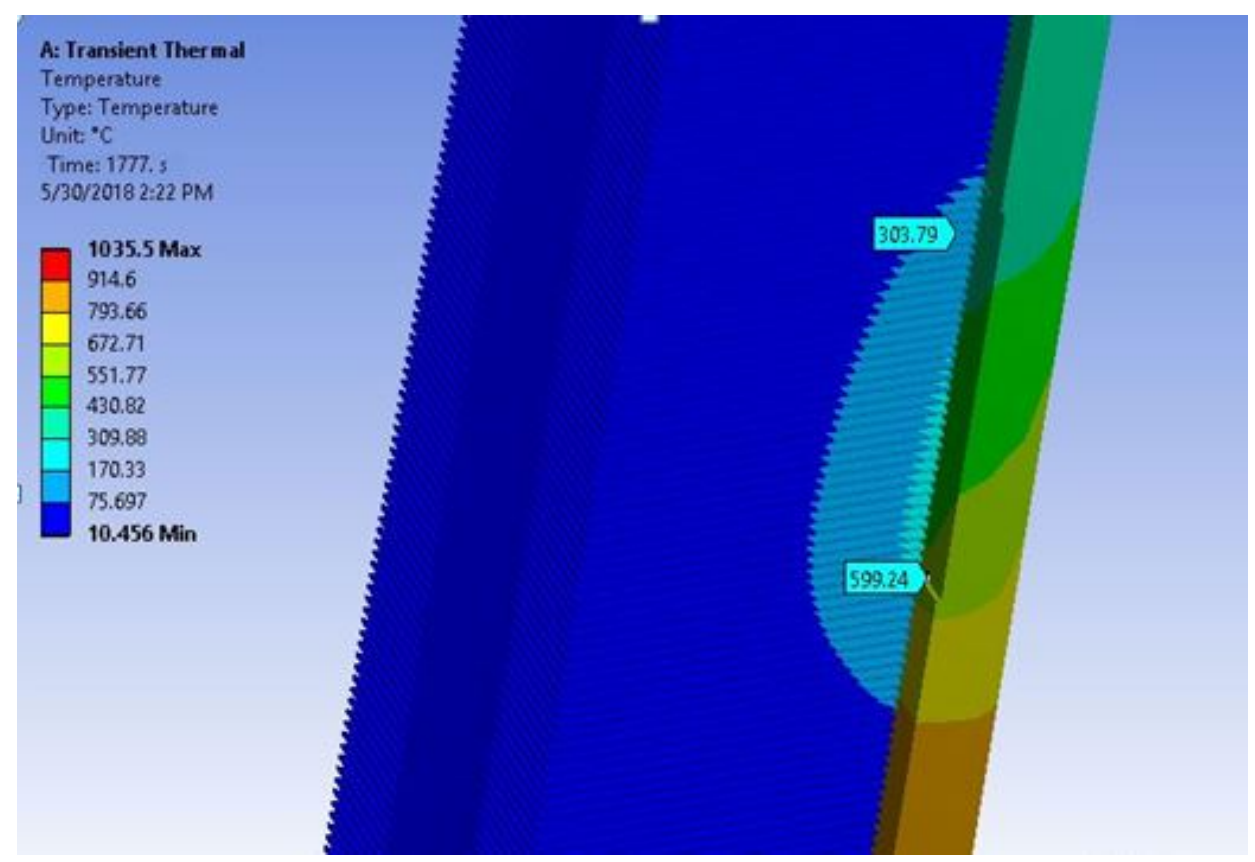

Figure 16. Probes showing maximum and minimum temperatures and the hot and cold sides of module respectively. 


\section{CONCLUSION}

The results found regarding temperature gradients and heat fluxes were in agreement with the required and the expected outcomes. The requirements and/or expectations were such that the produced gradients must engender the safe working temperature limits for the TEG module simultaneously producing appreciable results. The temperature difference of $296^{\circ} \mathrm{C}$ obtained across the module through numerical investigation was close to that in case of few implemented systems by companies like Ecogen Technology, when climatic conditions of South East Asian sub-continent were considered. Since, not much practical implementation of TEG system has been done to produce energy at commercial level hence not much data of comparison is available for that and hence the complete success of product depends on the experimentations conducted over the built prototype.

The outcomes of CFD simulation, related to thermal parameters were transported as input information to the transient thermal workbench.

The CFD results regarding contours of species' distribution, particularly the contours of fuel gas distribution (Fig 14), showed that a complete combustion reaction occurred under the given set of circumstances, an important conclusion that can be drawn from it is that the vent design of the lower portion of combustion chamber is perfect as to ensure a complete combustion without any external forced air input. Thus, CFD simulation validates the design of combustion chamber.

The simulations showed that the orientation of module over the aluminium envelope surface, with respect to length of the envelope, was correct as far as safe limit of hot side temperature, i.e. $600^{\circ} \mathrm{C}$, prescribed by catalogues $[8,9]$ is concerned.

Further, it was found that the temperature differences between cold and hot side of modules attained at steady state were in agreement with the prescribed safe limits which is within the limits of $550^{\circ} \mathrm{C}$ prescribed by the Ecogen technology catalogues [8, 9].

The modified fin panel shown in Fig. 6 was observed to have served its purpose and would indeed be a replacement for the one shown in Fig. 3.

The transient period, or charging time, after the formation of temperature gradient at the chamber side was found to be 1777 sec which equivalents to roughly 30 minutes. It was concluded to be in good agreement with set industrial constraints which recommend the total charging time to lie between 40 to 50 minutes. It is a limit set by the concerned clients for whom the systems are being designed. Thus the dimensions assigned to the designed models of critical components such as chamber, envelope and fin panels were validated by transient thermal analysis.

In all the geometries subjected to corresponding analytical studies, the mesh selection was fine relevance, sizing and medium smoothing. Moreover, selection of sectioned model for transient analysis not only saved solver and meshing time but also provided satisfactorily agreeable outcomes. Thus, the agreeable results show that the methodology utilised to analyse the problem was correct and novel.

Though the time period required for development of that temperature gradient at the chamber inner surface wasn't calculated, it can be included in the scope of further research which can be calculated using transient CFD simulation. Further, structural analysis of cage body, to check the durability and strength in off-shore situations as well as normal situations also remains scope of research.

The subsequent experimental validation of the results of the computational analysis and generation of power-temperature plots is to be conducted over the prototype, which would be a better way to define the energy balance sheet for this design than to simulate it because it is more of a practical aspect as far as energy efficiency is concerned. The validation would include output parameters like power, temperature gradients, charging time and efficiency (thermal and electrical) all to be measured and validated; although the temperature ranges and gradients simulated here give an initial expression of results being in agreement with the expectations. It, therefore, would open further research opportunities for the clean energy enthusiasts.

\section{ACKNOWLEDGEMENTS}

This work was supported by the Departments of Mechanical and Electrical engineering, Maulana Azad National Institute of Technology, Bhopal India and Ventures Studios, Ahmedabad University, India. The authors express their deep gratitude to them for providing access to softwares and materials.

\section{REFERENCES}

[1] Shakun W, Bearden JH, Henderson DR. Thermoelectric Generator. US4734139 1988.

[2] Arsie I, Cricchio A, Pianese C, Ricciardi V, DeCesare M. Modeling Analysis of Waste Heat Recovery via Thermo-Electric Generator and Electric Turbo-Compound for CO2 Reduction in Automotive SI Engines. 
ATI 2015 -70thConference of the ATI Engineering Association. Energy Procedia 2015; 82: 81 - 88. doi: 10.1016/j.egypro.2015.11.886.

[3] Kryotherm Inc. Introduction into thermo-electric power generation. Catalogue report.

[4] Liu C, Chen P, Li K. A 500W low temperature thermoelectric generator: Design and experimental study. International journal of hydrogen energy 2014; 39: 15497-15505. doi.org/10.1016/j.ijhydene.2014.07.163.

[5] Al-Habahbeh OM., Mohammad A, Al-khalidi A, Khanfer M, Obeid M. Design optimization of a largescale thermoelectric generator. Journal of King Saud University - Engineering Sciences 2018; 30: 177182. doi.org/10.1016/j.jksues.2016.01.007

[6] Aimable N. Design, modeling, and fabrication of thermoelectric generator for waste heat recovery in local process industry. University of Agder, 2017.

[7] Tang ZB, Deng YD, Su CQ, Shuai WW, Xie CJ. A research on thermoelectric generator's electrical performance under temperature mismatch conditions for automotive waste heat recovery system; Case Studies in Thermal Engineering 2015; 5: 143-150. .doi.org/10.1016/j.csite.2015.03.006.

[8] Ecogen Technology; Gas fuel thermo-electric generator GTEG 500-A; Catalogue report.

[9] Ecogen Technology, Thermo-Electric Generator systems Design and performance Catalogue; 2015.

[10] Cengel Y. Heat Transfer A Practical Approach: Second Edition; McGraw Hill Publication; 2002.

[11] Chen L, Meng F, Sun F. Maximum power and efficiency of an irreversible thermoelectric generator with a generalized heat transfer law. Scientia Iranica B 2012; 19:1337-1345. doi:10.1016/j.scient.2012.07.014

[12] Mackowski DW, Conduction of heat transfer notes for mech 7210. [Lecture] Mechanical Engineering Department; Auburn University, [Accessed 21th April 2020].

[13] Li W, Paul MC, Montecucco A, Siviter J, Knox AR, Sweet T, Gao M, Baig H, Mallick TK, Han G, Gregory DH, Azough F, Freer R. Multiphysics simulations of thermoelectric generator modules with cold and hot blocks and effects of some factors. Case Studies in Thermal Engineering 2017; 10: 63-72. doi.org/10.1016/j.csite.2017.03.005.

[14] Kim CN. Development of a numerical method for the performance analysis of thermoelectric generators with thermal and electrical contact resistances. Applied thermal engineering 2018; 1: 408-417. doi.org/10.1016/j.applthermaleng.2017.10.158.

[15] Rodrigo CRL, Manoel FMN; Danielle RSG. CFD modelling of small scale cyclonic combustor chamber using bio-mass powder. Energy Procedia 2017; 120: 556-563. doi.org/10.1016/j.egypro.2017.07.208.

[16] Hernik B, Latacz G, Znamirowski D. A numerical study on combustion process for various configurations of burners in the novel ultra supercritical BP-680 boiler furnace chamber. Fuel Processing Technology 2016; 152: 381-389. doi.org/10.1016/j.fuproc.2016.06.038.

[17] Turbulence Intensity wiki; CFD online; Available from: https://www.cfdonline.com/Wiki/Turbulence_intensity, [Accessed 21th April 2020].

[18] Keryeyen S, Ilbas M. Experimental and numerical analysis of turbulent premixed combustion of low calorific value coal gases in a generated premixed burner. Fuel 2018; 220: 586-598. doi.org/10.1016/j.fuel.2018.02.052.

[19] Yilbas BS, Ali H, Al-Sharafi A. Innovative design of a thermoelectric generator with extended and $\begin{array}{lllll}\text { segmented pin } \quad \text { configuration. } & \text { Applied }\end{array}$ doi.org/10.1016/j.applthermaleng.2017.05.066

[20] Thorp W. Design of thermo-electric generator modules using silicon-germanium alloy. Power sources. Elsevier 1967; 613-625. doi.org/10.1016/B978-0-08-012176-5.50045-1

[21] Meng JH, Zhang XX, Wang XD. Characteristic study and parametric study of a thermoelectric generator by considering variable material properties and heat losses. International journal of heat and mass transfer 2015; 80: 227-235. doi.org/10.1016/j.ijheatmasstransfer.2014.09.023.

[22] Duda P; A method of transient thermal load estimation and its application to identification of aerodynamic heating on atmospheric re-entry capsule; Aerospace science and technology 2016; 51: 26-33. doi.org/10.1016/j.ast.2016.01.015. 
[23] Nabil M, Khodadadi JM. Computational/analytical study of the transient hot wire-based thermal conductivity measurements near phase transition. International journal of heat and mass transfer 2017; 187: 895-907. doi.org/10.1016/j.ijheatmasstransfer.2017.04.043.

[24] Manjunath HN, Aithal SK, Kumar LH, Babu NR, Auradi V. Transient thermal investigations during external chilling of $\mathrm{Al}-18 \%$ Si Castings through experimental and finite element modelling. Materials today proceedings 2018; 5: 7191-7197. doi.org/10.1016/j.matpr.2017.11.385.

\section{ANNEXTURE 1}

Following assumptions were taken into consideration while conducting this study:-

1. Fin tip was assumed to be adiabatic or insulated.

2. Only methane, propane and butane were considered as constituents of fuel while other minor components were ignored.

3. Ambient air temperature for CFD as well as transient thermal study was assumed to be $35^{\circ} \mathrm{C}$ as per Indian sub continental climate.

4. Gas inlet temperature was assumed to be $30^{\circ} \mathrm{C}$ because the gas was assumed to be supplied under pressure. When released to a relatively open space, such as a combustion chamber, the sudden expansion cools down the gas to a certain degree and hence the inlet gas temperature was taken less than the ambient temperature.

5. Air inlet turbulence intensity is kept $5 \%$ because the flow is from a vent, which can be considered as a medium turbulence flow system having limits between $1 \%$ to $5 \%$ intensity; and evidently the maximum possible limit was selected [17].

6. Gas inlet turbulence intensity is kept as $20 \%$ because the system is a mass flow type which is indeed a high velocity variation and high entropy system thus the $20 \%$ limit was chosen [17].

7. Exhaust turbulence intensity was kept as $10 \%$ as the value has to lie between those of gas inlet and air inlet but surely to be within high turbulence limits. Hence a $10 \%$ value was assumed [17].

8. The walls of chamber were assumed to be perfectly smooth and hence internal heat transfer through microfins doesn't occur.

9. Steady state CFD was assumed.

10. Specific heat values and viscosity values were kept constant to abide by the simplified Fourier's law equation (2).

11. Silicon alone was chosen as a material for TEG module body to control the heat conduction.

12. Section model was taken to conduct the transient study and its overall behaviour was assumed to be similar to that of a complete unit under given set of boundary conditions. The parts of surfaces of $\mathrm{Al}$ envelope which were not in contact with the module body were set perfectly insulated while conducting transient study. Similarly the parts of backside side surfaces of fin panel which weren't in contact with module's cold side surface, were marked perfectly insulated. 